\title{
Physiological Responses Associated with Nordic-walking training in Systolic Hypertensive Postmenopausal Women
}

\author{
by \\ Ewelina Latosik ${ }^{1}$, Igor Z. Zubrzycki ${ }^{2,3}$, Zbigniew Ossowski3 , Olgierd Bojke ${ }^{3}$, \\ Anna Clarke 4 , Magdalena Wiacek ${ }^{3}$,Bartosz Trabka
}

Loss of physical strength and hypertension are among the most pronounced detrimental factors accompanying aging. The aim of this study was to evaluate the influence of a supervised 8-week Nordic-walking training program on systolic blood pressure in systolic-hypertensive postmenopausal women. This study was a randomized control trial on a sample of 24 subjects who did not take any hypertension medications. There was a statistically significant decrease in systolic blood pressure and an increase in lower and upper-body strength in the group following Nordic-walking training. There was a decrease in serum levels of total cholesterol, triglycerides, and low-density cholesterol. The obtained results indicate that an 8-week Nordic-walking program may be efficiently employed for counteracting systolic hypertension through a direct abatement of systolic blood pressure and an increase of maximal aerobic capacity.

Key words: postmenopause; hypertension; exercise; nordic-walking, functional fitness.

\section{Introduction}

Among many detrimental factors accompanying aging, loss of strength (McNeil et al., 2007) and deterioration of postural balance leading to an increased risk of fall accidents (Thornby, 1995) play the most profound role. Hence, maintaining an appropriate level of neuromuscular fitness - through physical exercises (Ferrari, 2007) - may prevent a social withdrawal caused by an age-dependent decline in physical activity (Wiacek et al., 2009).

This observation spurred the studies on prevention of age-related loss of strength (Perkins and Kaiser, 1961) as well as promotion of physical activity among older adults (Satariano and McAuley, 2003). Recent studies also suggest that the correlation between lower body strength and fall risk is nation dependent (Lipsitz et al., 1994), and that the number of falling accidents within a given community can be an indicator of functional abilities of that population ( $\mathrm{Li}$ et al., 2003).

An extended span of a human life is also accompanied by an age-dependent deterioration of health-related quality of life (HRQoL), driven, among others, by an increase in blood pressure (Landahl et al., 1986), which may lead to a range of cardiovascular diseases (Franklin, 1999) that result in an increased cost of medical welfare.

The aforementioned phenomena, i.e., increased blood pressure and a decreased level of physical fitness, incited a search for means, other than pharmaceutical, allowing to counteract agedependent deterioration of HRQoL.

During the last decade, a derivative of

1 - The Jerzy Kukuczka Academy of Physical Education in Katowice, ul. Mikołowska 72A, 40-065 Katowice, Poland.

2 - School of Health and Applied Sciences, Private Bag 13388, Windhoek, Namibia.

3 - Jędrzej Śniadecki Academy of Physical Education and Sport ul. Kazimierza Górskiego Gdańsk, Poland.

4 - Department of Microbiology and Biochemistry, University of Fort Hare, South Africa. 
walking (W) called Nordic-walking (NW) has become a very popular mode of physical activity in Central and Northern Europe. Its clinical viability, among young and elderly women, has already been confirmed in several studies (FigardFabre et al., 2011; Mikalacki et al., 2011).

Because of growing popularity of NW among Europeans, we made an attempt to test its efficacy in preventing hypertension in postmenopausal systolic-hypertensive women. For the purpose of our research we designed a moderate 8-week NW training program that comprised of three mesocycles, and carried out a randomized control trial under the null hypothesis that NW may be utilized as means of reducing systolic blood pressure in postmenopausal women.

\section{Material and Methods}

\section{Participants}

The following inclusion criteria were employed: last period $>12$ months ago, systolic blood pressure (SBP) $\geq 140 \mathrm{mmHg}$ and diastolic blood pressure (DBP) $<90 \mathrm{mmHg}$.

Exclusion criteria were: (a) SBP $\geq 180 \mathrm{mmHg}$ and/or DBP $\geq 90$ (b) taking anti-hypertensive drugs, (c) oophorectomy, (d) chemotherapy within six months before screening, (e) coronary artery disease, (f) renal failure, (g) rheumatoid arthritis, (h) pulmonary disease, (i) diabetes mellitus or type II diabetes treated with insulin, (j) myocardial infarction or surgery within six months before screening, (k) smoking of more than two cigarettes per day or consuming more than the equivalent of one glass of wine per day, and (l) inability to obtain approval for participation in the study form a primary-care physician.

Of 1200 women who agreed for the primary screening only 25 met all the criteria to participate in the study (Figure 1).

\section{Measures}

Laboratory tests and anthropometry

Body mass and height were measured using a standard scale and a stadiometer with accuracy of $0.1 \mathrm{~kg}$ and $0.5 \mathrm{~cm}$, respectively.

Resting SBP and DBP were registered using an Omron HEM-907XL apparatus (Omron Healthcare, Inc., IL, USA).

A fasting blood draw was completed to measure blood glucose, total cholesterol, triglycerides, and high- and low-density lipoprotein cholesterol. Serum lipid levels were measured on the first and the last days of the training program on an empty stomach using ARCHITECT ci8200 Integrated System, Abbott Diagnostic.

Subjects were advised to be well hydrated and to limit their physical activity one day before the laboratory test, as well as to remain physically inactive the evening before and the morning of the test.

\section{Peak oxygen uptake}

$\mathrm{VO}_{2 \max }$ peak was assessed by open-circuit spirometry using the following protocol: (a) the test was preceded by a 2 min warm up: walking at the speed of $2-3 \mathrm{~km} / \mathrm{h}$, (b) the subject started walking, without holding onto the handrails during the test, at $4 \mathrm{~km} / \mathrm{h}$ and $0 \%$ grade. The elevation was increased by $2 \%$ each 2 min stage until volitional fatigue. The test was continued until the subject could no longer continue due to an excessive elevation, achieved a respiratoryexchange ratio $>1.0$, a maximal heart rate greater than $\mathrm{HR}_{\max }=206-0.88^{*}$ age, or other clinical criteria for test termination were observed.

$\mathrm{VO}_{2 \max }$ was measured using a breath-by-breath gas-exchange system (MetaMax 3B, CortexMedical, Germany). In this study $\mathrm{VO}_{2 \max }$ data are expressed as $\mathrm{VO}_{2 \text { peak. }}$.

Assessment of the level of physical fitness

Functional fitness was assessed by means of a tailored Fullerton battery test including: a) chair stand (CST), b) arm curl (CURL). All tests were performed one hour after breakfast to avoid results skewing by daily activities.

Statistical Analyses

Changes induced by the training/sedentary period in an analyzed parameter were examined using the Wilcoxon signed-rank test. Differences between the groups were evaluated by means of the Wilcoxon rank sum test using the p-value of 0.05 as the statistical threshold.

Relative changes induced by the experiment were measured using a "natural" relative difference, employing a natural logarithm, denoted as log percent (L\%) (Tornqvist et al., 1985).

\section{Procedures}

Training Program

All exercise sessions were performed outdoors on a flat area, and consisted of a 10 to $12 \mathrm{~min}$ 
warm-up followed by $45 \mathrm{~min}$ of $\mathrm{NW}$ and a $10 \mathrm{~min}$ stretching. The NW program was divided into three mesocycles: I: 2 weeks of walking the distance of $3 \mathrm{~km}$, an average heart rate between $40-60 \%$ of an age-dependent maximal heart rate; $\mathrm{HR}_{\max }=206-0.88 \bullet$ (age) (Gulati et al., 2010), $\left[\left(\mathrm{HR}_{\max }-\mathrm{HR}_{\text {rest }}\right) \bullet(0.4\right.$ to 0.6$\left.)\right]+\mathrm{HR}_{\text {rest; }}$ II: 3 weeks walking the distance of $3.1 \mathrm{~km}$ with an average heart rate between $45-68 \%$, and III: 3 weeks of walking the distance of $3.8 \mathrm{~km}$ with an average heart rate between $38-69 \%$. The heart rate was monitored using a GARMIN Forerunner 405 apparatus.

\section{Diet}

The following dietary guidelines were followed during the experiment: (a) consume en gros $~ 2.51$ water/day, (b) $130 \mathrm{~g} /$ day of carbohydrates, (c) $0.8 \mathrm{~g}$ of protein per kilogram of body mass assessed at baseline, (d) $20-30 \%$ of total calories should be covered by fat, (e) no eating after 7 P.M. or three hours before sleep, and (f) four meals a day. Allsubjects were preconditioned using the above outlined guidelines two weeks before the start of the experiment.

\section{Results}

Basic statistics of the baseline and experimental period are presented in Table 1.

The supervised NW program significantly decreased SBP, and increased upper and lowerbody strength in the experimental group. Furthermore, a positive trend in body mass, WC, $\mathrm{HC}, \mathrm{DBP}, \mathrm{VO}_{2 \max }, \mathrm{TC}, \mathrm{TG}$ and LDL-C levels was observed.

The control group was defined by an unfavorable augmentation in body mass, TG, and LDL-C, and a decrease in lower-body strength.

Although SBP and DBP diminished in both groups, changes in SBP and DBP in the control group were relatively 1.6 and 3.4 smaller than those in the experimental group, respectively.

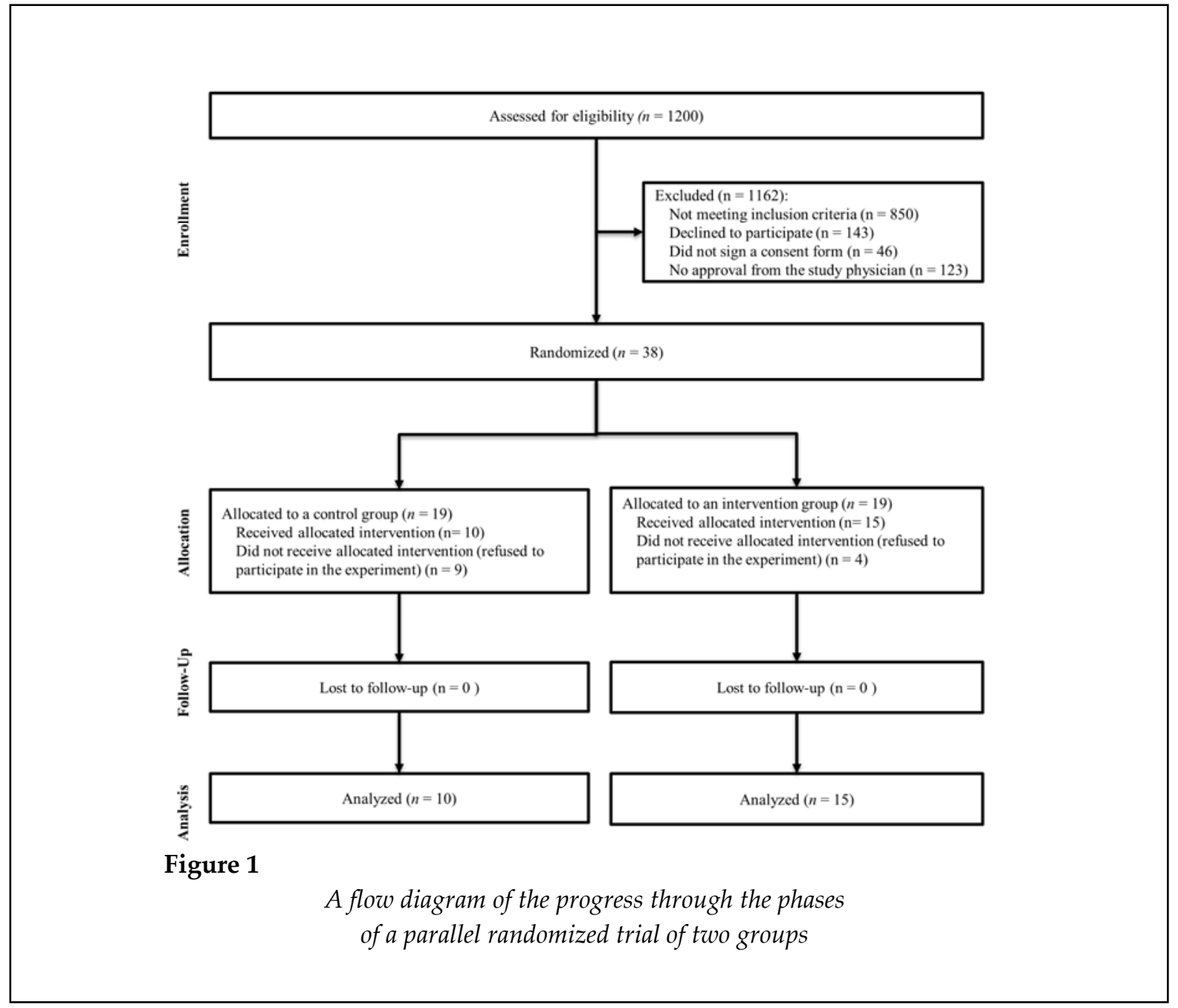


Table 1

Differences in anthropometry, serum lipids, physical performance, and functional fitness at baseline and after an 8-week

Nordic-walking training program in systolic hypertensive postmenopausal women

\begin{tabular}{|c|c|c|c|c|c|c|c|c|}
\hline Variable & Cont $(0)$ & $\operatorname{Ex}(0)$ & Cont (8) & $\mathrm{p}$ & $\operatorname{Ex}(8)$ & $\begin{array}{c}\mathrm{L} \% \\
\text { Con } \\
t\end{array}$ & L\% Ex & $\begin{array}{l}\mathrm{p} \\
\mathrm{Ex}\end{array}$ \\
\hline \multicolumn{9}{|l|}{ Anthropometry } \\
\hline $\begin{array}{l}\text { Body weight } \\
\text { (kg) }\end{array}$ & $\begin{array}{c}76.8(69.6, \\
80.8)\end{array}$ & $77.2(69.6,79)$ & $78(71,78.6)$ & & $75.4(69,78.8)$ & 0.67 & -1.02 & \\
\hline BMI $\left(\mathrm{kg} / \mathrm{m}^{2}\right)$ & $\begin{array}{c}28.2(25.2 \\
32)\end{array}$ & $28.2(26,32.4)$ & $27.4(26,32)$ & & $\begin{array}{c}28.4 \\
(26,31.4)\end{array}$ & -1.25 & 0.31 & \\
\hline$W C(\mathrm{~cm})$ & $\begin{array}{c}93.8(86.6, \\
97.6)\end{array}$ & $\begin{array}{c}95 \\
(87,99)\end{array}$ & $\begin{array}{c}94.8 \\
(87,101.4)\end{array}$ & & $91.2(82.6,96)$ & 0.46 & -1.77 & \\
\hline $\mathrm{HC}(\mathrm{cm})$ & $\begin{array}{c}105.8(103 \\
113)\end{array}$ & $\begin{array}{c}107 \\
(103,114)\end{array}$ & $\begin{array}{c}108.4(104.8 \\
119.4)\end{array}$ & & $105(102,118)$ & 1.05 & -0.82 & \\
\hline WHR & $0.8(0.8,0.8)$ & $0.8(0.8,0.8)$ & $0.8(0.8,0.8)$ & & $0.8(0.8,0.8)$ & 0 & 0 & \\
\hline \multicolumn{9}{|l|}{$\begin{array}{l}\text { Cardiovascular } \\
\text { fitness }\end{array}$} \\
\hline SBP (mmHg) & $\begin{array}{r}149.4 \\
(147.2 \\
149.6)\end{array}$ & $\begin{array}{c}145.8(143 \\
150.4)\end{array}$ & $\begin{array}{c}142.8(141.2 \\
150.2)\end{array}$ & & $\begin{array}{c}135.6(126.6 \\
141.6)\end{array}$ & -1.96 & -3.15 & $a$ \\
\hline DBP (mmHg) & $\begin{array}{c}86.8(85.2 \\
87.4)\end{array}$ & $85.2(83.4,87.4)$ & $86.2(83,89)$ & & $83.2(78.4,88)$ & -0.3 & -1.03 & \\
\hline \multicolumn{9}{|l|}{ Physical fitness } \\
\hline $\begin{array}{l}\mathrm{VO}_{2 \max } \\
(\mathrm{ml} / \mathrm{kg} / \mathrm{min})\end{array}$ & $\begin{array}{c}29.6(24.2 \\
29.8)\end{array}$ & $28.8(25.4,30.4)$ & $29.4(24.2,31.4)$ & & $30.6(28.6,31.6)$ & -0.29 & 2.63 & \\
\hline Curl (rep/min) & $18(18,19)$ & $17.6(17,19)$ & $20(18,22)$ & & $22.6(20.6,24.6)$ & 4.58 & 10.86 & $a$ \\
\hline Cst (rep/min) & $16(15,16)$ & $15(15,16)$ & $15(15,17)$ & $b$ & $19(17,20)$ & -2.8 & 10.27 & $a$ \\
\hline \multicolumn{9}{|l|}{ Serum lipids } \\
\hline $\mathrm{TC}(\mathrm{mmol} / \mathrm{L})$ & $6.2(4.6,6.4)$ & $6(4.6,6.6)$ & $6.2(4.4,6.4)$ & & $5.4(4.4,6)$ & 0 & -4.58 & \\
\hline $\mathrm{TG}(\mathrm{mmol} / \mathrm{L})$ & $1(0.8,1.6)$ & $1(0.8,1.4)$ & $1.2(1,1.4)$ & $b$ & $0.8(0.8,1)$ & 7.92 & -9.69 & \\
\hline HDL (mmol/L) & $1.8(1.8,2)$ & $2(1.6,2)$ & $2(1.6,2)$ & & $2(1.4,2.2)$ & 4.58 & 0 & \\
\hline LDL (mmol/L) & $3.2(2.8,4)$ & $3.4(2.6,4)$ & $3.6(2.6,4)$ & & $3(2.6,3.4)$ & 5.12 & -5.44 & \\
\hline
\end{tabular}

$B M I=$ Body Mass Index; Ex = exercise group; Cont = control group;

$T C=$ total cholesterol; $T G=$ triglycerides; $H D L-C=$ high-density cholesterol;

$L D L-C=$ low-density cholesterol; $W C=$ waist circumference; $H C=$ hip circumference;

$W H R=$ waist/hip ratio; $S B P=$ systolic blood pressure, $D B P=$ diastolic blood pressure;

$V_{2 m a x}=$ maximal oxygen capacity; $C$ url = arm bend test, $C s t=$ chair stand test;

$a-p$-value less than 0.05 for differences in medians induced by the experiment;

$b$ - $p$-value less than 0.05 for differences in means/medians between the experimental group and control group for the specific period of the experiment.

\section{Discussion}

We studied postmenopausal women who did not take any anti-hypertensive drugs during the $1^{\text {st }}$ and $2^{\text {nd }}$ stage of hypertension (2004), and assessed changes in anthropometric, cardiorespiratory, and functional fitness variables as a function of an 8-week supervised NW program.
A dearth of information on modulation of isolated hypertension (ISH) through physical exercises, leads to inconsistent conclusions; for example, Ferrier et al. (2001) showed that ISH could not be modulated by means of short-term aerobic training, whereas Westhoff et al. (2007) indicated that blood pressure, including ISH, could be modulated through physical exercises.

However, a comparison of current results with 
previous findings regarding the influence of NW on HRQoL (Hagner et al., 2009) in healthy postmenopausal women, unfolds many positive interrelations between aerobic exercises such as Nordic-walking and parameters defining HRQoL: (a) a non-significant increase in $\mathrm{VO}_{2 \max }$ equal to $2.63 \mathrm{~L} \%$ in this study versus a significant increase of $4 \mathrm{~L} \%$ in the latter, i.e., 12-week aerobic NW training which comprised of three $90 \mathrm{~min}$ sessions, (b) a non significant decrease of $1.77 \mathrm{~L} \%$ vs. a significant decrease of $6.90 \mathrm{~L} \%$ in WC, (c) a non-significant decrease of $4.58 \mathrm{~L} \%$ vs. a significant decrease of $6.12 \mathrm{~L} \%$ in TC, (d) a nonsignificant decrease of $9.69 \mathrm{~L} \%$ vs. a significant decrease of $3.17 \mathrm{~L} \%$ in TG, (e) lack of changes in HDL-C vs. a non-significant increase of $6.57 \mathrm{~L} \%$ in HDL-C, (f) a non-significant decrease of $5.44 \mathrm{~L} \%$ vs. a significant decrease of $7.38 \mathrm{~L} \%$ in LDL-C, and $(\mathrm{g})$ a non-significant increase in the BMI of $0.31 \mathrm{~L} \%$ vs. a significant decrease of $4.77 \mathrm{~L} \%$ in the BMI.

Although, we were not able to confirm a significant decrease in the BMI of postmenopausal women who had undergone a supervised NW program, as shown in previous studies (Hagner et al., 2009), we observed a beneficial role of a supervised Nordic-walking training program in preventing cardiovascular diseases, caused by ISH.
Additionally, we also showed that the use of walking poles during NW exercises lead not only to an enhancement in oxygen uptake (Hansen and Smith, 2009), but also improves strength of the lower and upper-body.

A conjunction of delineated relations between changes in physiological variables and the NW program with the results of the study on physical fitness and coronary risk factors (Takamiya et al., 2000) makes it transparent that through changes in $\mathrm{VO}_{2 \max } \mathrm{SBP}$ can be modulated. We conjectured that NW was superior than $\mathrm{W}$ and jogging (Schiffer et al., 2006) for rehabilitation of hypertensive subjects.

\section{Conclusions}

Hypertension has become one of the most profound health problems among the elderly in many societies. This spurred a search for a means, other than pharmaceutical, allowing to maintain proper blood pressure in elderly subjects.

In this study we showed that a supervised 8week NW program could be effectively employed for averting detrimental changes in SBP in systolic-hypertensive postmenopausal women.

\section{Acknowledgements}

The presented research was partially supported by the grant RSA2 05352 awarded to IZZ.

\section{References}

The Seventh Report of the Joint National Committee on Prevention, Detection, Evaluation, and Treatment of High Blood Pressure. Bethesda (MD); 2004

Brown M, Holloszy JO. Effects of walking, jogging and cycling on strength, flexibility, speed and balance in 60- to 72-year olds. Aging (Milano), 1993; 5(6): 427-434

Ferrari CK. Functional foods and physical activities in health promotion of aging people. Maturitas, 2007; 58(4): 327-339

Ferrier KE, Waddell TK, Gatzka CD, Cameron JD, Dart AM, Kingwell BA. Aerobic exercise training does not modify large-artery compliance in isolated systolic hypertension. Hypertension, 2001; 38(2): 222-226

Figard-Fabre H, Fabre N, Leonardi A, Schena F. Efficacy of Nordic Walking in Obesity Management. Int J Sports Med, 2011; 32(6): 407-414

Franklin SS. Ageing and hypertension: the assessment of blood pressure indices in predicting coronary heart disease. J Hypertens Suppl, 1999; 17(5): S29-36

Gulati M, Shaw LJ, Thisted RA, Black HR, Bairey Merz CN, Arnsdorf MF. Heart rate response to exercise stress testing in asymptomatic women: the st. James women take heart project. Circulation, 2010; 
122(2): 130-137

Hagner W, Hagner-Derengowska M, Wiacek M, Zubrzycki IZ. Changes in level of VO2max, blood lipids, and waist circumference in the response to moderate endurance training as a function of ovarian aging. Menopause, 2009; 16(5): 1009-1013

Hansen EA, Smith G. Energy expenditure and comfort during Nordic walking with different pole lengths. J Strength Cond Res, 2009; 23(4): 1187-1194

Landahl S, Bengtsson C, Sigurdsson JA, Svanborg A, Svardsudd K. Age-related changes in blood pressure. Hypertension, 1986; 8(11): 1044-1049

Li F, Fisher KJ, Harmer P, McAuley E, Wilson NL. Fear of falling in elderly persons: association with falls, functional ability, and quality of life. J Gerontol B Psychol Sci Soc Sci, 2003; 58(5): P283-290

Lipsitz LA, Nakajima I, Gagnon M, Hirayama T, Connelly CM, Izumo H, Hirayama T. Muscle strength and fall rates among residents of Japanese and American nursing homes: an International Cross-Cultural Study. J Am Geriatr Soc, 1994; 42(9): 953-959

McNeil CJ, Vandervoort AA, Rice CL. Peripheral impairments cause a progressive age-related loss of strength and velocity-dependent power in the dorsiflexors. J Appl Physiol, 2007; 102(5): 1962-1968

Mikalacki M, Cokorilo N, Katic R. Effect of nordic walking on functional ability and blood pressure in elderly women. Coll Antropol, 2011; 35(3): 889-894

Perkins L, Kaiser H. Results of short term isotonic and isometric exercise programs in persons over sixty. Phys Ther Rev, 1961; 41: 633-635

Satariano WA, McAuley E. Promoting physical activity among older adults: from ecology to the individual. Am J Prev Med, 2003; 25(3 Suppl 2): 184-192

Schiffer T, Knicker A, Hoffman U, Harwig B, Hollmann W, Struder HK. Physiological responses to nordic walking, walking and jogging. Eur J Appl Physiol, 2006; 98(1): 56-61

Takamiya T, Shimomitsu T, Odagiri Y, Ohya Y, Sakamoto A, Katsumura T, Murase N, Naka M, Kajiyama J. The relationship between physical fitness and coronary risk factor profiles in Japanese women. Environ Health Prev Med, 2000; 5(1): 6-12

Thornby MA. Balance and Falls in the Frail Older Person - a Review of the Literature. Topics in Geriatric Rehabilitation, 1995; 11(2): 35-43

Tornqvist L, Vartia P, Vartia YO. How Should Relative Changes Be Measured. American Statistician, 1985; 39(1): 43-46

Westhoff TH, Franke N, Schmidt S, Vallbracht-Israng K, Meissner R, Yildirim H, Schlattmann P, Zidek W, Dimeo F, van der Giet M. Too old to benefit from sports? The cardiovascular effects of exercise training in elderly subjects treated for isolated systolic hypertension. Kidney Blood Press Res, 2007; 30(4): 240-247

Wiacek M, Hagner W, Hagner-Derengowska M, Bluj B, Drozd M, Czereba J, Zubrzycki IZ. Correlations between postural stability and strength of lower body extremities of women population living in long-term care facilities. Archives of Gerontology and Geriatrics, 2009; 48(3): 346-349

\section{Corresponding author:}

\section{Igor Z. Zubrzycki}

School of Health and Applied Sciences

Polytechnic of Namibia

Private Bag 13388, 13 Storch Street,

Windhoek, NAMIBIA

Email: igorzubrzycki@yahoo.com 